\title{
Correction to: Total Neoadjuvant Therapy for Locally Advanced Rectal Cancer: PRODIGE 23 Trial
}

\author{
Martin R. Weiser, MD \\ Department of Surgery, Memorial Sloan Kettering Cancer Center, New York
}

CORRECTION TO: ANN SURG ONCOL (2022) 29:1493-1495 https://doi.org/10.1245/s10434-021-11104-9

In the original online version of this article, the next to last paragraph on page 1494 describing the PROSPECT trial had an error. The corrected sentence is as follows:
Patients are randomized to induction chemotherapy (FOLFOX or CAPOX) or standard chemoradiation. Patients in the experimental arm that have $\geq 20 \%$ response to induction chemotherapy go directly to surgery while those with lesser response receive chemoradiation.

The original article was corrected.

Publisher's Note Springer Nature remains neutral with regard to jurisdictional claims in published maps and institutional affiliations.

The original article can be found online at https://doi.org/10.1245/ s10434-021-11104-9.

(C) Society of Surgical Oncology 2022

Published Online: 26 April 2022

M. R. Weiser, MD

e-mail: Weiser1@mskcc.org 